\title{
Significance of intraocular lens power calculation
}

\author{
MOHINDER SINGH AND ALIAS DAHALAN \\ From the Department of Ophthalmology, National University of Malaysia, Kuala Lumpur, Malaysia
}

SUMMARY A total of 94 patients underwent extracapsular cataract extraction and insertion of Sinsky style two-loop posterior chamber intraocular lenses. Forty-six eyes received a standard power IOL and 48 eyes were given a preoperatively calculated IOL. A significant difference was found in the two groups with regard to the postoperative refractive error and uncorrected visual acuity.

Posterior chamber intraocular lens (IOL) implantation is rapidly becoming the preferred method of visual rehabilitation after cataract surgery. Patients opting for intraocular lenses nowadays demand the best optical correction. To achieve ideal and optimum results, estimation of correct IOL power is necessary. The precision of such calculations depends mostly on the accuracy of ultrasonic bio-

Correspondence to Mohinder Singh, FRCS, 37 Norman Road, Ilford, Essex IG1 2NH. metery as well as corneal curvature measurements.

With the increasing availability of lens implants in the third world, a great majority of patients will have their aphakia corrected by intraocular lenses in the near future. A-scan biometry is unlikely to be within the reach of many practising ophthalmologists in these countries. Very few studies have compared the outcome of implanting a standard powered and an individually tailored posterior chamber IOL.' We report such a study with a view to assessing the significance of calculating the IOL power preoperatively.

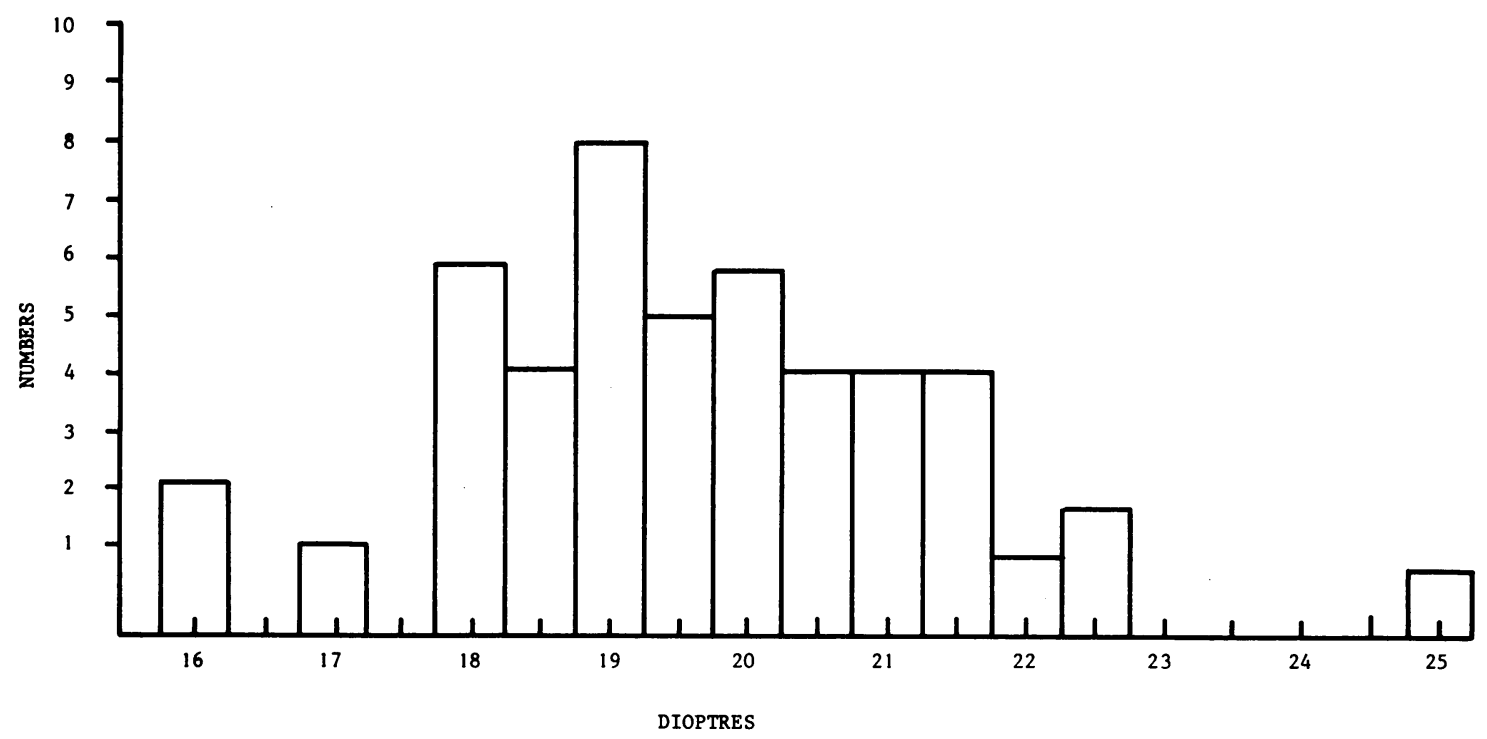

Fig. 1 Range of intraocular lenses used in the measured group. 


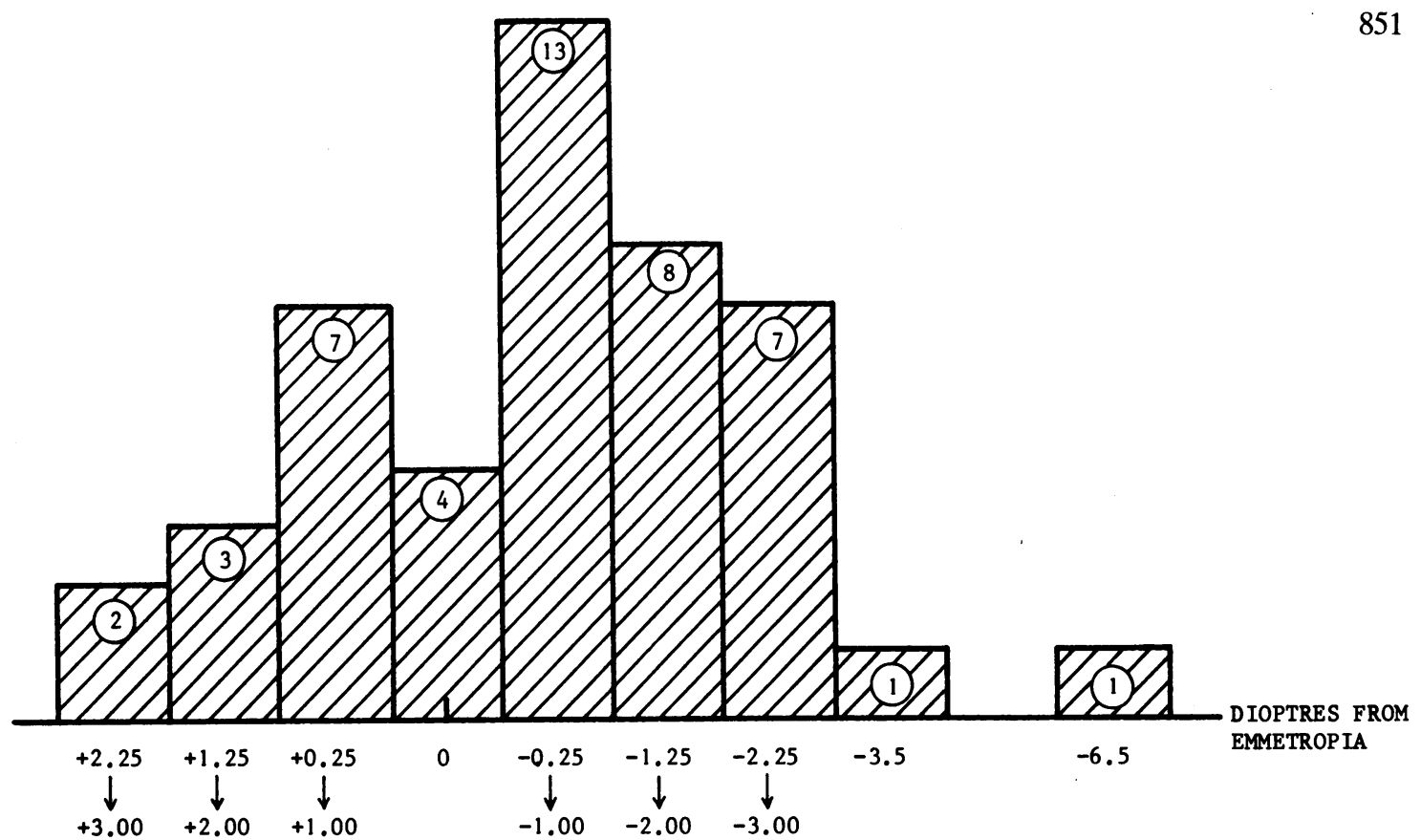

Fig. 2 Difference between the postoperative spherical equivalent refraction and emmetropia. Unmeasured group $n=46$.

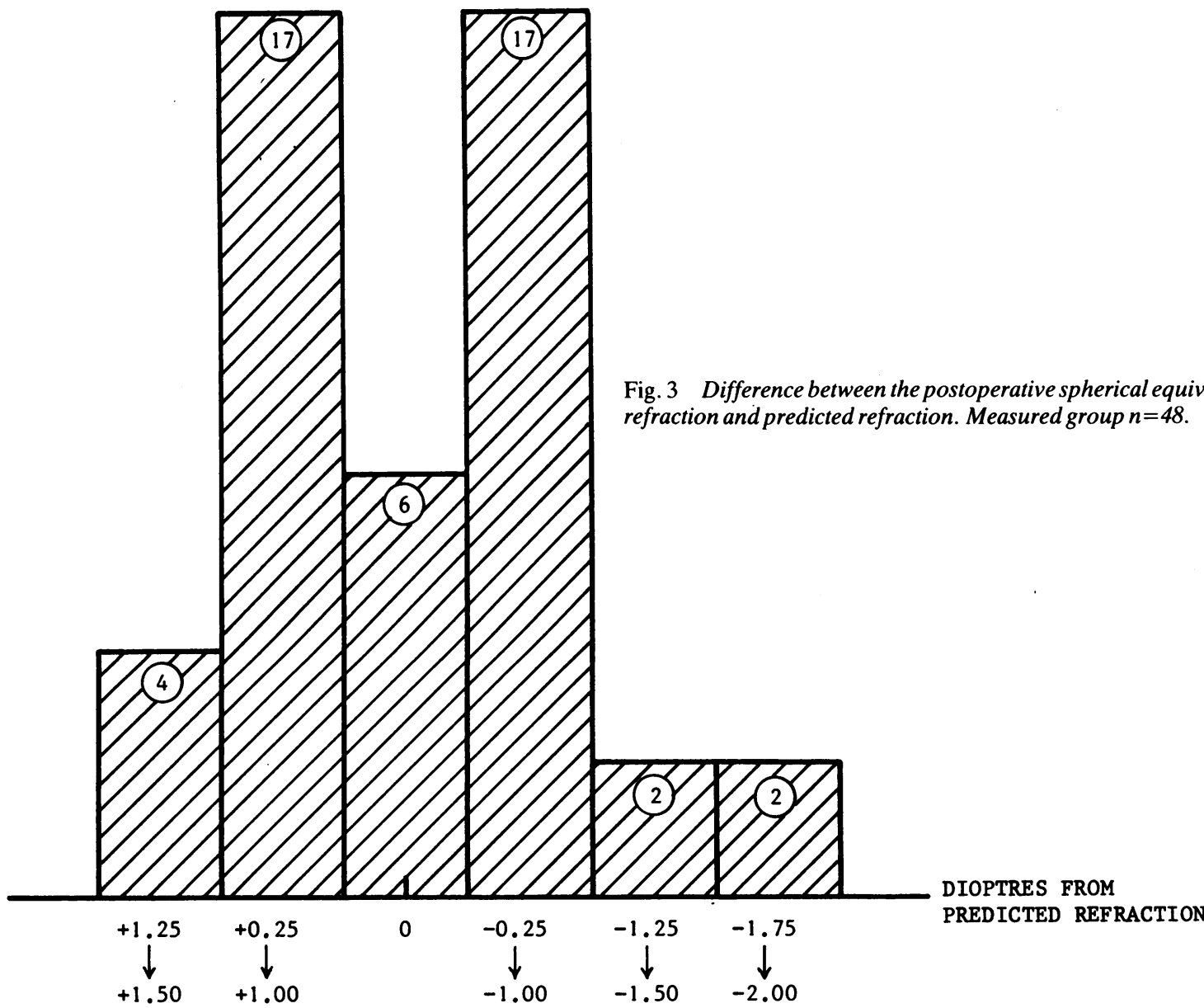




\section{Material and methods}

Ninety-four patients were operated upon under general anaesthesia and with a Zeiss operating microscope. A standard extracapsular cataract extraction was performed by using the McIntyre manual aspiration system. A Sinsky style two-loop posterior chamber IOL was inserted by the same surgeon (MS). No viscoelastic material was used in this series. The limbal wound was closed with six to seven 10/0 monofilament sutures.

The first group of consecutive 46 patients received a standard power IOL of 19.5 dioptres, \pm 0.5 dioptre, depending on availability. The second group of consecutive 48 patients had their IOL power estimated preoperatively. Axial length measurements were done with Cooper Vision Ultrascan digital A, which uses an applanation transducer. The corneal curvature was measured with a Bausch and Lomb keratometer. The IOL power required to produce 1 dioptre myopia was calculated by computing the SRK formula. ${ }^{23}$

All patients were refracted between 8 and twelve weeks after surgery. The postoperative residual spherical equivalent refraction was determined for every pseudophakic eye. Patients having postsurgical astigmatism greater than 2 dioptres were not considered for the study.

\section{Results}

The 'unmeasured' group consisted of 46 patients. Their ages varied between 28 and 77 years, mean 57.8 years. The 'measured' group consisted of 48 cases. Their ages ranged from 35 to 80 years, mean 59.3 years. The intraocular lenses implanted in the measured group ranged from 16 to 25 dioptres (Fig. 1).

The postoperative visual acuity is shown in Table 1. The postoperative corrected visual acuity was similar in the two groups. However, there was a significant difference in the uncorrected postoperative visual acuity in the two groups $(p<0 \cdot 5) .58 \cdot 3 \%$ of the patients in the measured group could see $6 / 12$ or better uncorrected as compared with only $32.6 \%$ in the unmeasured group. Only $12.5 \%$ of cases in the measured group had uncorrected vision below $6 / 18$, whereas $43.5 \%$ of patients in the unmeasured group had vision worse than $6 / 18$.

Fig. 2 shows the distribution of the difference between the spherical equivalent refraction and emmetropia for the unmeasured group. $52 \%$ of the patients fell within $1 \mathrm{D}$ of emmetropia, $95.6 \%$ within 3 D. There were two patients outside this range measuring $-3.5 \mathrm{D}$ and $-6.5 \mathrm{D}$ postoperative residual pseudophakic refractive error.
Table 1 Postoperative visual acuity

\begin{tabular}{|c|c|c|c|c|}
\hline \multirow[t]{2}{*}{ Vision } & \multicolumn{2}{|c|}{ Uncorrected } & \multicolumn{2}{|l|}{ Corrected } \\
\hline & $\begin{array}{l}\text { Measured } \\
\text { group }\end{array}$ & $\begin{array}{l}\text { Unmeasured } \\
\text { group }\end{array}$ & $\begin{array}{l}\text { Measured } \\
\text { group }\end{array}$ & $\begin{array}{l}\text { Unmeasured } \\
\text { group }\end{array}$ \\
\hline $6 / 5$ & 1 & 0 & 10 & 8 \\
\hline $6 / 6$ & 4 & 2 & 23 & 22 \\
\hline $6 / 9$ & 8 & 5 & 12 & 14 \\
\hline $6 / 12$ & 15 & 8 & 3 & 2 \\
\hline $6 / 18$ & 14 & 11 & 0 & 0 \\
\hline $6 / 24$ & 4 & 3 & 0 & 0 \\
\hline $6 / 36$ & 2 & 9 & 0 & 0 \\
\hline $6 / 60$ & 0 & 8 & 0 & 0 \\
\hline
\end{tabular}

Fig. 3 shows the distribution of the difference between the spherical equivalent refraction and predicted refraction for the measured group. In this group $83.3 \%$ of the cases fell within $1 \mathrm{D}$ of the predicted refraction and $100 \%$ within 2 D. $66 \cdot 6 \%$ of eyes in this group showed postoperative refraction within $2 \mathrm{D}$ of myopia (Fig. 4). $87 \cdot 5 \%$ of cases were within $1 \mathrm{D}$ of the expected refraction.

\section{Discussion}

Calculation of IOL power preoperatively helps to achieve a desired refraction and avoid unexpected high ametropia. ${ }^{+}$It has been shown to be useful even for planned ametropia in those patients who have a large refractive error in the fellow eye. ${ }^{5}$ The accuracy of IOL power estimation in this study is similar to that found in previously reported series. ${ }^{67}$ Our study has shown that patients who received calculated IOLs achieved a much better uncorrected visual acuity than those in the unmeasured group, though there was little difference in the corrected visual acuity in both groups. Unexpected high refractive error was not present in the measured group, whereas two such cases were encountered in the unmeasured group. Similar observations have been reported by other workers. ${ }^{468}$ Our data show that the margin of refractive error can be significantly reduced by preoperative determination of lens power.

Ultrasonic lens power estimation is not available to every implant surgeon in the developing countries. Insertion of a standard power lens and correction of the residual pseudophakic refractive error by a contact lens or spectacles is the only other alternative to practise. Intraocular lens power can also be determined clinically if the surgeon can evaluate the patient's basic refraction. Binkhorst ${ }^{4}$ has outlined the possible sources of error in the clinical determination of lens power. It is extremely difficult if not impossible to obtain the basic refraction in most cases in an Asian population. However, reasonably good results 


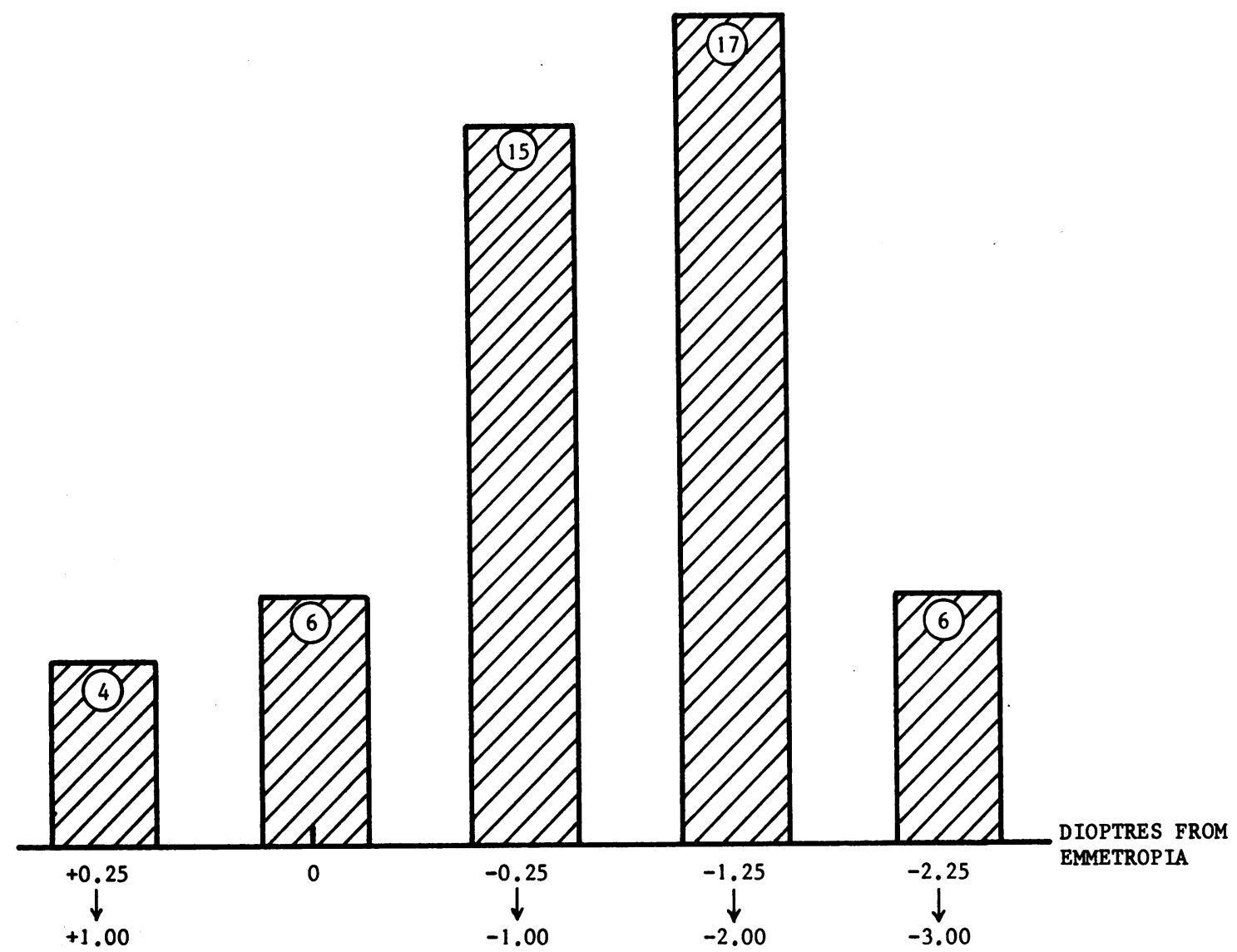

Fig. 4 Difference between the postoperative spherical equivalent refraction and emmetropia. Measured group $n=48$.

have been reported by implanting a standard power IOL. ${ }^{18}$ In our measured group the majority $(68 \%)$ of the lenses inserted ranged from 18 to 20.5 dioptres. An appropriate range of lenses most suitable for the local population can be reasonably determined by conducting a pilot study using preoperative ultrasonography coupled with the knowledge of postoperative residual pseudophakic refractive error. Hence the routine use of lens calculation may be dispensed with if the resources to carry it out are limited. A careful selection of patients might reduce unexpected surprises but will not eliminate them, and both the patient as well as the surgeon should be prepared to face them.

\section{References}

1 Thompson SM, Mohan-Roberts V. A comparison of postopera- tive refractive results with and without intraocular lens power calculation. BrJ Ophthalmol 1986; 70: 22-5.

2 Retzlaff J. A new intraocular lens calculation formula. J Am Intraocul Implant Soc 1980; 6: 148.

3 Sander DR, Kraff MC. Improvement of intraocular lens power calculation using empirical data. J Am Intraocul Implant Soc 1980; 6: 263.

4 Percival P. Lens power calculation - is it necessary? Trans Ophthalmol Soc UK 1983; 103: 577-9.

5 Hillman JS. Intraocular lens power calculation for planned ametropia: a clinical study. $\mathrm{Br} J$ Ophthalmol 1983; 67: 255-8.

6 Hillman JS. The selection of intraocular lens power by calculation and by reference to the refraction - a clinical study. Trans Ophthalmol Soc UK 1982; 102: 495-7.

7 Hoffer KJ. Accuracy of ultrasound intraocular lens calculation. Arch Ophthalmol 1981; 99: 1819-23.

8 Kraff MC, Sanders DR, Leiberman HL. Determination of intraocular lens power. A comparison with and without ultrasound. Ophthalmic Surg 1978; 9: 81-4.

9 Binkhorst RD. Pitfalls in the determination of intraocular lens power without ultrasound. Ophthalmic Surg 1976; 7: 69-72.

Accepted for publication 31 October 1986. 